\title{
COMPARATIVE STUDY BETWEEN VARIOUS TOPICAL AGENTS IN PROMOTION OF WOUND HEALING IN DIABETIC FOOT
}

\author{
Umesh Raj Somasundaram¹, Sabarimalai Palanisamy²
}

${ }_{1}^{1}$ Assistant Professor, Department of General Surgery, Melmaruvathur Adhiparasakthi Institute of Medical Sciences and Research, Melmaruvathur, Tamilnadu, India.

${ }^{2}$ Assistant Professor, Department of General Surgery, Melmaruvathur Adhiparasakthi Institute of Medical Sciences and Research, Melmaruvathur, Tamilnadu, India.

\begin{abstract}
\section{BACKGROUND}

Foot care amongst diabetics is incredibly important, as foot related complications are common. Majority of diabetic patients develop foot ulcer at one point of time or the other during the course of the illness. Foot ulcers and amputations are the major cause of morbidity, disability as well as emotional and physical cost for people with diabetes. Therefore, routine dressing plays an important role in healing. Traditional form of dressing in diabetic foot is done with Normal Saline. Wide variety of new dressings have been developed.

The aim of this study is to compare the efficacy of topical agents namely normal saline, phenytoin, placental extract and collagen dressing in promotion of wound healing in diabetic foot ulcer.
\end{abstract}

\section{MATERIALS AND METHODS}

This is a non-randomised controlled trial, done over a period of 5 months from August 2013 to December 2013 in Madras Medical College Hospital, Tamilnadu. 120 patients with diabetic foot ulcer were selected randomly and divided into four groups and topical agents of normal saline, phenytoin, placental extract and collagen sheets were applied. Patients were prospectively analysed for wound healing. Phenytoin dressing compared with other dressings has good and faster healing rate in diabetic foot ulcer.

Methodology- This is a non-randomised controlled trial. The patients who were admitted in Department of General Surgery, Madras Medical College Hospital, Tamilnadu, tertiary care teaching institution during the study period were screened. 120 patients were randomly divided into 4 groups and treated with normal saline, phenytoin dressing, placental extract and collagen dressing. The factors studied were reduction in ulcer size, culture on day 10, need for second debridement and time for granulation.

\section{RESULTS}

Phenytoin dressing promoted rapid wound healing and also needed lesser repeat debridement and lesser hospitalisation compared to other agents in study.

\section{CONCLUSION}

Topical phenytoin is a novel cost-effective agent in diabetic foot ulcer for rapid wound healing reducing the morbidity and ensure faster return to normal day-to-day activities.

\section{KEY WORDS}

Diabetic Foot Ulcer, Topical Phenytoin, Placental Extract, Collagen Dressing, Wound Healing.

HOW TO CITE THIS ARTICLE: Somasundaram UR, Palanisamy S. Comparative study between various topical agents in promotion of wound healing in diabetic foot. J. Evolution Med. Dent. Sci. 2018;7(30):3436-3442, DOI: 10.14260/jemds/2018/774

\section{BACKGROUND}

Diabetes Mellitus is a long-term metabolic disorder that is characterised by high blood sugar, insulin resistance and relative lack of insulin. The long-term complications being neuropathy and vasculopathy, which becomes a predominant factor for developing diabetic ulcers. Foot is the most vulnerable part of body for injury and infection, which is often neglected by the patient. As diabetic wounds take long time to heal it causes severe psychological, social and physical morbidity for the patient.

'Financial or Other Competing Interest': None.

Submission 28-02-2018, Peer Review 10-07-2018,

Acceptance 16-07-2018, Published 23-07-2018.

Corresponding Author:

Umesh Raj Somasundaram,

No. C8, Doctors Quarters,

Hospital Road, Melmaruvathur-603319,

Kanchipuram-District, Tamilnadu, India.

E-mail: drumeshraj@gmail.com

DOI: $10.14260 /$ jemds $/ 2018 / 774$

(c) (i) $(9)$
About $50 \%$ of diabetic ulcers often result in nontraumatic surgical amputation and therefore there is a need for treating the ulcer at the earliest in an economical way using cost-effective topical agents. ${ }^{1}$ In this study, we have tried to evaluate and compare the effectiveness of topical agents namely normal saline, phenytoin, placental extract and collagen dressing in diabetic foot.

Phenytoin has been highly effective anti-convulsant agent and in recent times has been used to treat chronic wounds in its topical form. It heals wound by stimulation of fibroblast proliferation and enhancing formation of granulation tissue. It decreases collagenase activity and inhibits glucocorticoid activity. It has also got anti-bacterial activity. It increases gene expression of platelet derived growth factor in macrophages and monocytes promoting wound healing.

Collagen is body's framework, which forms an important role in healing of wounds. It is obtained from many sources like bovine porcine and human. Bovine collagen sheets were used in the present study. Diabetic patients stall in the first stage of wound healing and cannot lay down collagen. 
Fibroblast and keratinocytes, parts of collagen play a key role in skin development.

Human placental aqueous extract provides lot of nourishment to wound and helps in healing wound much faster. Contents include RNA, DNA, ATP, vitamin B6, B5 riboflavin, biotin, PABA, folic acid, methylcobalamin and many other factors. It has corticotropin-releasing growth factor like activity and keratinocyte proliferating activity.

\section{MATERIALS AND METHODS}

This is a non-randomised controlled trial done over a period of 5 months from August 2013 to December 2013 and the study area was Department of General Surgery, Madras Medical College, a tertiary care teaching centre in Tamilnadu, India. It is taken by convenient sample size technique since the duration of the study was 1 year. Patients admitted for diabetes with foot ulcer during the study period were screened and those who fulfilled the inclusion criteria were included in the study. Finally, sample size of 120 was arrived at using $95 \%$ confidence interval and $80 \%$ power. 15 of this, 30 were randomly allocated to each of the four groups.

Parameters of this study were the duration of hospital stay, healing rate, reduction of ulcer size and culture of bacterial organisms.

\section{The Inclusion Criteria were-}

1. Patients with diabetic foot ulcer with Wagner's grade 1 and 2.

2. Patients with good glycaemic control.

3. Patients willing for the study.

\section{The Exclusion Criteria were-}

1. The patients who had major vasculopathy.

2. Patients who were allergic to the topical agents.

3. Those who did not give consent for the study.

4. Uncontrolled diabetes.

\section{Subject Allocation}

The patients with above inclusion criteria were included and the agent was allocated randomly, so that each group contained 30 subjects.

\section{Application of Dressing}

Before application of dressing, the patient underwent sharp surgical debridement. The Group A were dressed with normal saline.

\section{The Study Groups B, C and D were with Phenytoin, Placental Extract and Collagen Respectively- \\ Group B}

Phenytoin tablet was crushed and then mixed with $5 \mathrm{~mL}$ of NS and gauze was immersed in the suspension and spread evenly across the ulcer and left for 24 hours till next dressing.

\section{Group C}

Human placental aqueous extract gel was applied to the ulcer area and the dressing was changed.

\section{Group D}

The collagen sheet was thoroughly squeezed and rinsed with normal saline and was firmly applied to the ulcer area. The dressing was changed once in 3 days.

The patient's ulcer area was measured with gauze piece and then transferred to a graph paper and the area was measured in $\mathrm{cm} 2$. The wound was monitored everyday for healthy granulation tissue. On the tenth day, culture was repeated. The patient's glycaemic status was under control. The area of ulcer was again measured on day 21. The measurements were done by an independent observer who was blinded for the study. The patients who underwent consequent wound debridement were also noted.

\section{Statistical Methods}

Statistical analysis was performed using SPSS software (version 17.0 for windows SPSS Inc., Chicago, II, USA). The normality of the data was assessed using KolmogorovSmirnov's test. Quantitative variables were expressed as mean \pm SD and qualitative variables were presented as proportions. The associations between the variables were calculated using Pearson's Chi-square test, Fisher's exact test, One-Way ANOVA with LSD post-hoc test. P-value $<.05$ was considered as the level of significance.

\section{RESULTS}

A total of 120 patients were selected for the study on the basis of Inclusion and Exclusion criteria. Out of them, patients were randomly classified under Groups A, B, C, D who underwent normal saline, phenytoin, placental extract and collagen dressings respectively and a comparative study was made between the groups. The baseline characteristics remained indifferent between the groups (Table 1). According to the study, patients who underwent Phenytoin dressing were found to have increased rapidity of healing, reduction of ulcer size, whereas the least rapidity of healing found with the Normal Saline dressing. The persons of the age group 40 - 60 years were predominant in the group with 32 being the youngest and 60 being the oldest. The mean age of the patient included was 46.5. Male Diabetics were more prone for diabetic foot ulcer. In this study, the males formed the majority with their number being 78. The number of females was 42 .

The culture on Day 0 and Day 10 was taken. Appropriate antibiotics were administered. Table 2 shows the effectiveness of all modalities of treatment in the respective groups. Comparatively, in the phenytoin group the number of ulcers that became culture negative was 21 . In the placental group extract it was 17 , in the collagen group it was 12 , whereas in the control NS group it was 9. The mean hospitalisation was least in the phenytoin group with 22 , whereas 26, 28 and 35 in the placental extract, collagen and NS respectively. The percentage of reduction of ulcer size was highest in the phenytoin group being 64.9 and 52.05; 30.8 and 26.9 in placental extract, collagen and NS group respectively. The number of patients who needed second debridement were 9, 9, 18 and 20 in the phenytoin, placental extract, collagen and NS respectively. 


\begin{tabular}{|c|c|c|c|c|c|c|c|c|c|c|}
\hline & \multicolumn{2}{|c|}{$\begin{array}{c}\text { Group-A } \\
(n=30)\end{array}$} & \multicolumn{2}{|c|}{$\begin{array}{c}\text { Group-B } \\
(n=30)\end{array}$} & \multicolumn{2}{|c|}{$\begin{array}{c}\text { Group-C } \\
(n=30)\end{array}$} & \multicolumn{2}{|c|}{$\begin{array}{c}\text { Group-D } \\
(n=30)\end{array}$} & \multirow[t]{2}{*}{$\chi^{2}$} & \multirow[t]{2}{*}{ P-value } \\
\hline & No & $\%$ & No & $\%$ & No & $\%$ & No & $\%$ & & \\
\hline \multicolumn{11}{|c|}{ Gendera } \\
\hline Male & 20 & 66.7 & 19 & 63.3 & 18 & 60.0 & 21 & 70.0 & \multirow{2}{*}{.86} & \multirow{2}{*}{.73} \\
\hline Female & 10 & 33.3 & 11 & 36.7 & 12 & 40.0 & 9 & 30.0 & & \\
\hline \multicolumn{11}{|c|}{ Site of Lesionb } \\
\hline Left foot & 17 & 56.7 & 13 & 43.3 & 17 & 56.7 & 19 & 63.3 & \multirow{2}{*}{2.5} & \multirow{2}{*}{.49} \\
\hline \multirow[t]{3}{*}{ Right foot } & 13 & 43.3 & 17 & 56.7 & 13 & 43.3 & 11 & 36.7 & & \\
\hline & \multicolumn{2}{|c|}{ Group-A } & \multicolumn{2}{|c|}{ Group-B } & \multicolumn{2}{|c|}{ Group-C } & \multicolumn{2}{|c|}{ Group-D } & \multirow{2}{*}{ F-value } & \multirow{2}{*}{ P-value } \\
\hline & Mean & SD & Mean & SD & Mean & SD & Mean & SD & & \\
\hline $\begin{array}{c}\text { Age } \\
\text { (in years) }\end{array}$ & 46.1 & 6.7 & 46.1 & 6.4 & 48.3 & 6.9 & 45.7 & 6.5 & .91 & .43 \\
\hline $\begin{array}{l}\text { Duration } \\
\text { (days) }\end{array}$ & 4.37 & 2.8 & 3.7 & 2.6 & 4.23 & 2.6 & 3.93 & 2.5 & .38 & .76 \\
\hline 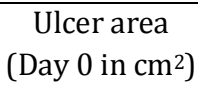 & 30.0 & 3.6 & 31.6 & 2.0 & 31.4 & 2.1 & 29.3 & 2.1 & 1.19 & .08 \\
\hline & $\begin{array}{l}\text { Group } \\
\text { arson c }\end{array}$ & $\begin{array}{l}\text { Iorma } \\
\text { quare }\end{array}$ & $\begin{array}{l}\text { ine, Gro } \\
\text { used; b }\end{array}$ & $\begin{array}{l}\text { Phen } \\
\text { er's ex } \\
\text { p-va }\end{array}$ & $\begin{array}{l}\text { Group } \\
\text { est used } \\
.05 \text { is si }\end{array}$ & $\begin{array}{l}\text { acenta } \\
\text { ne-Wa } \\
\text { cant }\end{array}$ & $\begin{array}{l}\text { act, D- } \\
\text { JOVA w }\end{array}$ & $\begin{array}{l}\text { gen at } \\
\text { SD pos }\end{array}$ & $\begin{array}{l}\text { cation; } \\
\text { oc test use }\end{array}$ & \\
\hline & & & able 1. & line $\mathrm{Ch}$ & teristics & he Stu & opulati & & & \\
\hline
\end{tabular}

\begin{tabular}{|c|c|c|c|c|c|c|c|c|c|c|}
\hline & \multicolumn{2}{|c|}{$\begin{array}{l}\text { Group-A } \\
(n=30)\end{array}$} & \multicolumn{2}{|c|}{$\begin{array}{c}\text { Group-B } \\
(n=30)\end{array}$} & \multicolumn{2}{|c|}{$\begin{array}{l}\text { Group-C } \\
(n=30)\end{array}$} & \multicolumn{2}{|c|}{$\begin{array}{c}\text { Group-D } \\
(n=30)\end{array}$} & \multirow[t]{2}{*}{$\chi^{2}$} & \multirow[t]{2}{*}{ P-value } \\
\hline & No & $\%$ & No & $\%$ & No & $\%$ & No & $\%$ & & \\
\hline \multicolumn{11}{|c|}{ Secondary Debridement } \\
\hline Done & 20 & 66.7 & 7 & 23.3 & 9 & 30.0 & 18 & 60.0 & \multirow{2}{*}{16.78} & \multirow{2}{*}{.001} \\
\hline Not done & 10 & 33.3 & 23 & 76.7 & 21 & 70.0 & 12 & 40.0 & & \\
\hline \multicolumn{11}{|c|}{ Culture on Day 10} \\
\hline Positive & 21 & 70.0 & 9 & 30.0 & 13 & 43.3 & 20 & 66.7 & \multirow[b]{2}{*}{13.1} & \multirow{2}{*}{.004} \\
\hline \multirow[t]{3}{*}{ Negative } & 9 & 30.0 & 21 & 70.0 & 17 & 56.7 & 10 & 33.3 & & \\
\hline & \multicolumn{2}{|c|}{ Group-A } & \multicolumn{2}{|c|}{ Group-B } & \multicolumn{2}{|c|}{ Group-C } & \multicolumn{2}{|c|}{ Group-D } & \multirow{2}{*}{ F-value } & \multirow{2}{*}{ P-value } \\
\hline & Mean & SD & Mean & SD & Mean & SD & Mean & SD & & \\
\hline $\begin{array}{l}\text { Granulation time } \\
\text { (in days) }\end{array}$ & 22.4 & 1.7 & 15.1 & 1.8 & 19.0 & 2.5 & 20.1 & 1.2 & 75.2 & $<.001$ \\
\hline $\begin{array}{c}\text { Duration of } \\
\text { hospitalisation } \\
\text { (in days) }\end{array}$ & 34.6 & 4.7 & 21.6 & 1.8 & 26.4 & 3.4 & 27.9 & 1.3 & 86.9 & $<.001$ \\
\hline $\begin{array}{c}\text { Ulcer area } \\
\left(\text { Day } 21{\left.\mathrm{in} \mathrm{cm}^{2}\right)}^{2}\right.\end{array}$ & 22.0 & 3.5 & 11.2 & 1.7 & 14.9 & 2.1 & 20.3 & 2.1 & 117.4 & $<.001$ \\
\hline $\begin{array}{l}\text { Percentage } \\
\text { decline }\end{array}$ & 27.0 & 3.8 & 65.0 & 4.7 & 52.1 & 3.7 & 30.7 & 2.4 & 685.9 & $<.001$ \\
\hline & & & est $\mathrm{u}$ & $\begin{array}{l}\text { - On } \\
\text { ralue }\end{array}$ & $\begin{array}{l}\text { y ANO } \\
\text { is sig }\end{array}$ & $\begin{array}{l}\text { vith LS } \\
\text { ant }\end{array}$ & t-hoc & used; & & \\
\hline
\end{tabular}

\section{Pre-Treatment}
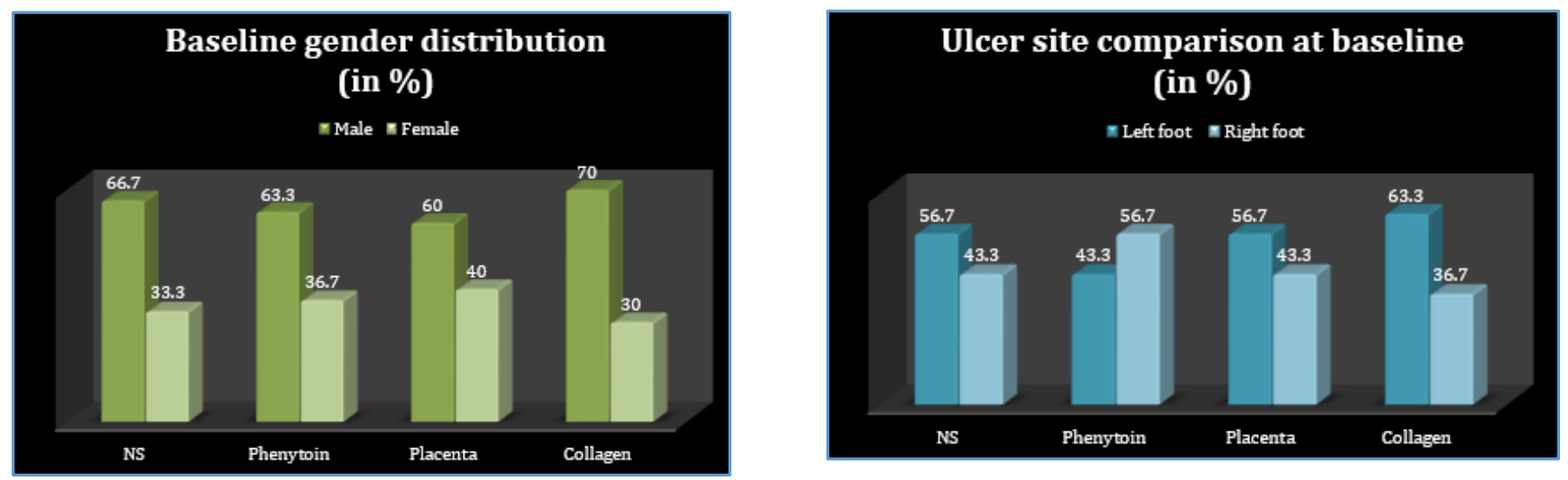

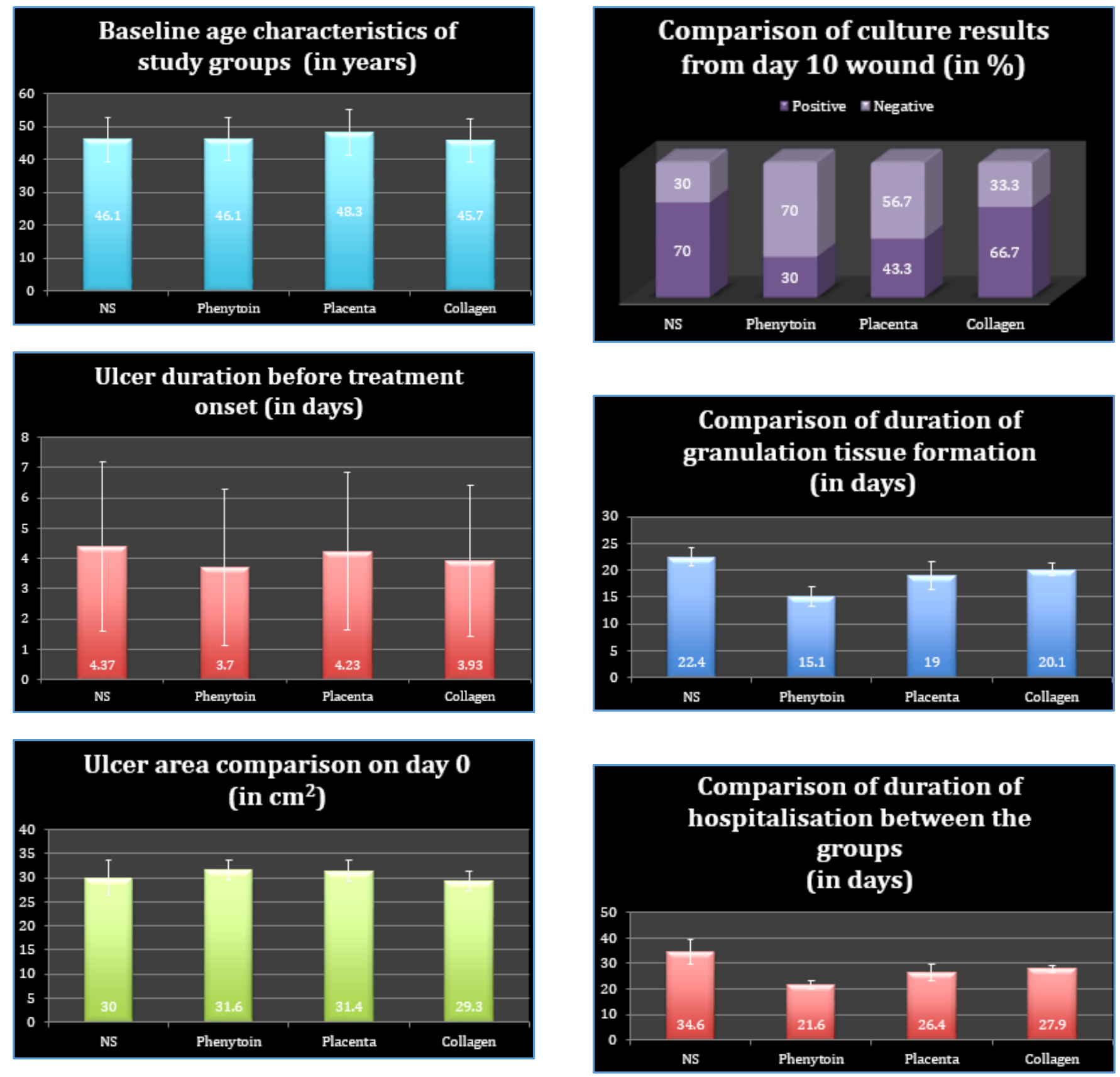

Post Treatment
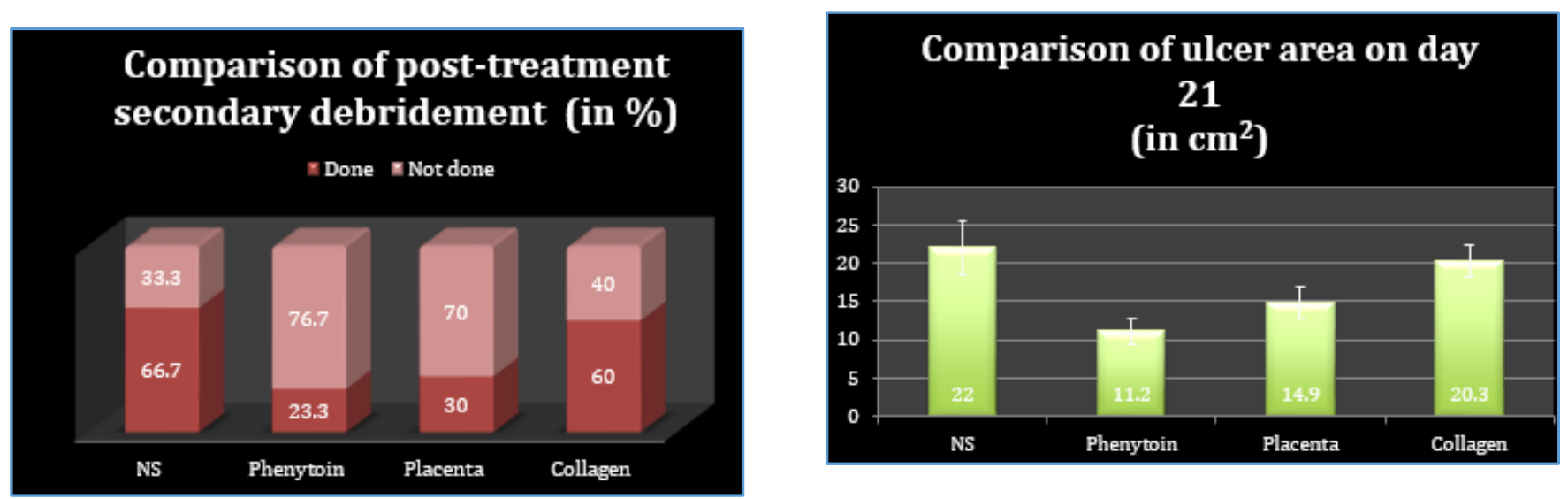


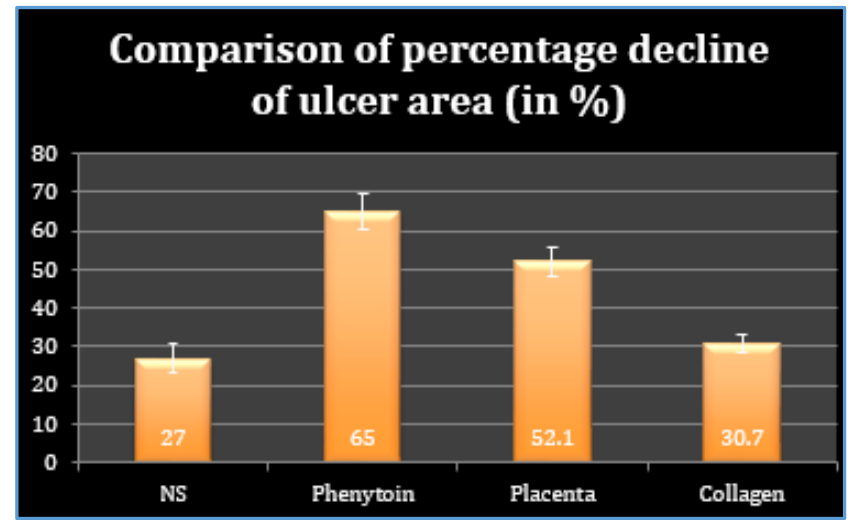

\section{DISCUSSION}

Diabetes is one among the commonest in the society. The long-standing uncontrolled diabetes causes peripheral vascular changes and neurological changes, which aggravates the disease course as diabetic foot ulcers. Diabetic foot ulcers are in an inflammatory phase and therefore the epidermal growth or migration has ceased over the ulcer. The search for a novel topical agent for rapid healing of diabetic foot still continues. This study aims to compare different topical agents, which are easily available in the community-based surgical practice.

\section{Topical Phenytoin}

\section{Chemical Structure of Phenytoin}

In year of 1938, Meritt and Putnam put out their results using phenytoin to treat seizures. Phenytoin has been a highly effective anticonvulsant since that time. Even now it continues to be a highly effective anti-seizure and antiarrhythmic drug.

Phenytoin used in trigeminal neuralgia and also to treat ulcers, epidermolysis bullosa and inflammatory condition. Many allergy and idiosyncratic cutaneous side effects have been observed. Undesirable side effect is gingival hyperplasia, mainly in children. ${ }^{2}$ This side effect indicate that it can induce connective tissue growth and might have the unique ability to promote wound healing. The valuable influence of phenytoin in wound healing had been described in 1945 and was witnessed in the first clinical test for wounds in gingiva in 1958. Since then the effectiveness of topical phenytoin has been established by numerous clinical trials for various types of wounds. ${ }^{3}$

\section{Postulated Mechanisms of Action}

Wound healing is a complicated process requiring the collaboration of many groups of cells and the mechanism by which phenytoin promotes wound healing is not fully understood, but several theories have been proposed. Phenytoin encourages the wound healing by fibroblast proliferation and increased granulation tissue formation, which is improved by reduction of collagenase activity, blocking glucocorticoid activity, antibacterial action either directly or indirectly affecting the inflammatory cells providing neovascularization. ${ }^{4}$ Phenytoin also stimulates gene expression of the PDGF beta chain in the cells of reticuloendothelial system namely macrophages.

\section{Diabetic Foot Ulcers}

Use of topical phenytoin against control therapy in 100 noninsulin dependent diabetic patients with foot ulcer was studied in a prospective trial, a sterile occlusive dressing applied daily. In control group, phenytoin powder was applied in a "thin layer" to the ulcer surface, then dry dressing daily in the study group. 21 days was mean healing time in the study group compared to 45 days in the control group.

Topical Phenytoin in diabetic foot ulcer, a study conducted in 1991 by Muthukumaraswamy MG et al ${ }^{5}$ showed the mean time of complete healing of diabetic foot ulcers were 21 days with Phenytoin dressing and 45 days with sterile occlusive dressing. The difference seen were statistically significant $(\mathrm{p}<0.05)$.

Topical Phenytoin in Diabetic ulcer, a double-blind control study conducted by Pai MRSM, Shrivastava N, Kotian MS, showed that there was an acceleration of wound healing in the Phenytoin group, particularly around 3rd week, but overall reduction in size of the ulcer was not statistically significant $(p>0.05){ }^{6}$

\section{Topical Phenytoin Preparation Reported Side Effect}

Patients tolerate topical phenytoin well. The systemic absorption was very minimal. Hypersensitivity to topical phenytoin is rare, burning sensation initially, skin rash occurred but resolved with subsequent application. 7,8

A systematic review of literature done between 1963 and 2005 shows that use of topical phenytoin on healing of wound has positive effect on wound healing.

\section{Collagen}

The Collagen is body's framework, which forms an important role in healing of wounds. The Collagen has been obtained from many sources, bovine, porcine fish and human. It is available in various forms as sheets and as powder. The present study aims to evaluate the role of bovine Collagen sheets in healing of chronic diabetic foot ulcers.

\section{Collagen sheets are used in-}

- 2nd degree superficial and deep dermal burns.

- Skin donor sites.

- Traumatic loss of skin cover.

- Temporary wound cover in major open fractures before definitive flap cover.

- Chronic skin ulcer.

- Shallow pressure sores.

- Leprosy ulcers.

- Dermabrasion areas.

\section{How Collagen can Speed Wound Healing}

Collagen plays an important role in the wound healing process. Originally thought to be the framework of wound healing and the provider of structural support for all other processes to take place, collagen controls many other cellular functions necessary to heal a wound. These functions include cell shape and differentiation as well as migration and synthesis of a number of proteins.

Patients with diabetes stall in the first stage of wound healing and cannot lay down collagen. Collagen affects every phase of wound healing. The hyperglycaemia caused by decreased insulin availability and increased resistance to insulin can affect the cellular response to tissue injury. In diabetes mellitus insulin is not in adequate supply, energy from carbohydrates cannot enter cells, the body cannot 
synthesize protein and lipolysis occurs. Fibroblast and keratinocytes, parts of collagen play a key role in skin development. ${ }^{9}$

\section{Sources of Collagen}

Living and non-living bovine- cattle, porcine- pig and equine horse's skin. Using a native proprietary process, they are harvested, a bioscaffold matrix is formed that steadies the vascular and cell components, which become merged into the wound bed. In a study done by Cullen et al, ${ }^{10}$ they used oxygenised regenerated cellulose (ORC)/ collagen dressing. The fluid from wound was analysed and found a marked reduction of collagenase-like activity; matrix metalloproteinase (MMP)-2 and MMP-9 levels. The growth factor binding was more and raised scavenger free radicals. Harmony between ECM degradation and production is necessary for optimal wound healing. Lack of extracellular matrix formation is the basic problem in non-tendency of diabetic wound to heal. ECM are believed to be broken down by bacteria. Fluid from wound on analysis yielded the following results- increased levels of proteases, raised inflammatory cytokines and reduced growth factors.

One big drawback in managing diabetic foot ulcers with collagen-based dressings is some bacteria's known attraction for collagen. Many bacteria isolated from wounds such as $\mathrm{S}$. aureus, E. faecalis and S. equi can bind to collagen by using adhesions of the bacterial surface component identifying adhesive matrix molecules family. Bacterial interaction with collagen dressings and their effect on wound healing still needs more research

\section{Placental Extract}

Nature is still providing man with abundant pleasures and things to the mankind despite the fact that man only attempts to destroy it. Chronic wound is still a mystery to the medical science. The medical advancements continue to try and find a solution to this one. Placenta, the organ of nourishment of growing foetus has provided an answer to this question. Placental aqueous extract has been proved to heal chronic wounds. It provides a lot of nourishment to the wound and help in healing wound much faster.

Phenytoin, a well-known anti-convulsant drug used in clinical practice and in recent times has been used to heal chronic wounds too in its topical form. The interest was triggered from the fact that it causes gingival hyperplasia as a side effect. Many studies have been done to demonstrate its healing capacity.

\section{Human Placental Aqueous Extract}

It is derived from human placenta.

\section{Contents}

Alkaline phosphatase and acid phosphatase, glutamate and oxaloacetate, ribonucleic Acid, deoxyribonucleic acid and ATP. Vitamin B6, B10, Riboflavin, B5, Biotin, PABA, Folic acid and Methylcobalamin.

Alanine, Tryptophan, Valine, Leucine. Fatty acids, steroids and trace elements.

It has Corticotropin-Releasing Factor (CRF)-like activity, growth factor-like activity, pigmenting activity and keratinocyte-proliferating activity. 11

\section{Normal Saline}

It is an age-old agent. It is used as wound dressing. It is nontoxic. It does not cause any hypersensitivity reactions, does not inhibit normal wound healing and also does not change the normal bacterial flora of the skin. It is very common, easily available, cost-effective, cheap dressing which can be easily stored.

In this study it was found that there was better healing with the use of phenytoin dressing in a diabetic foot ulcer compared to placental extract, collagen and NS. In this study the baseline characteristics such as the age, sex and location of the ulcer were similar in the patients in study groups.

A lot of studies in clinical medicine prove that phenytoin reduces the bacterial load of wounds. Topical phenytoin was reported to eliminate S. aureus, E. coli, K. oxytoca and P. aeruginosa from wounds within 7 - 9 days. This has been again confirmed in this study. In animal studies, it was observed that phenytoin more readily cleared gram -ve organisms than gram +ve organisms from wounds.

\section{CONCLUSION}

Phenytoin dressing promotes rapid wound healing in diabetic foot ulcers compared to other agents. Reduction in ulcer size was higher compared to other agents.

The culture negativity was higher in the phenytoin group, as it possibly could have anti-infective effect. The need for second debridement was also less in phenytoin group. Duration of hospitalisation was less in phenytoin group. Phenytoin dressing proved to be a superior topical agent which is cost effective, readily available and also easier to apply. Placental extract also has good healing rate and commercially available, but less cost effective compared to phenytoin. Collagen sheets are costly, and they have slower healing rate compared to other agents.

Hence, topical phenytoin is a novel cost-effective agent in diabetic foot ulcer for rapid wound healing reducing the morbidity and ensure faster return to normal day-to-day activities.

\section{REFERENCES}

[1] Shahi SK, Kumar A, Kumar S, et al. Prevalence of diabetic foot ulcer and associated risk factors in diabetic patients from North India. The Journal of Diabetic Foot Complications 2012;4(3):83-91.

[2] Talas G, Brown RA, McGrouther DA. Role of phenytoin in wound healing - a wound pharmacology perspective. Biochem Pharmacol 1999;57(10):108594.

[3] Modaghegh S, Salchian B, Tavassoli M, et al. Use of phenytoin in healing of war and non-war wounds, a pilot study of 25 cases. Int J Dermatol 1989;28(5):34750 .

[4] Anstead GM, Hart LM, Sunahara JF, et al. Phenytoin in wound healing. Ann Pharmacol 1996;30(7-8):768-75.

[5] Muthukumaraswamy MG, Sivakumar G, Manoharan G. Topical phenytoin in diabetic foot ulcers. Diabetes Care 1991;14(10):909-11.

[6] Pai MR, Sitaraman N, Kotian MS. Topical Phenytoin in diabetic ulcer: a double blind controlled trial. Ind J Med Sci 2001;55(11):593-9. 
[7] Pendse AK, Sharma A, Sodani A, et al. Topical phenytoin in wound healing. Int $J$ Dermatol 1993;32(3):214-7.

[8] Lodha SC, Lohiya ML, Vyas MC, et al. Role of phenytoin in healing of large abscess cavities. Br J Surg 1991;78(1):105-8.

[9] Brett D. A review of collagen and collagen-based wound dressings. Wounds 2008;20(12):347-56.
[10] Cullen B, Watt PW, Lundqvist C, et al. The role of oxidised regenerated cellulose/collagen in chronic wound repair and its potential mechanism of action. Int J Biochem Cell Biol 2002;34(12):1544-56.

[11] Chakraborty PD, Bhattacharyya D. Aqueous extract of human placenta as a therapeutic agent in Recent Advances in Research on the Human Placenta Rijeka, Croatia: In Tech Publishers 2012: p. 77-92. 